\title{
Erratum to: Metabolic growth theory: market-share competition, learning uncertainty, and technology wavelets
}

\section{Ping Chen}

\section{Erratum to: J Evol Econ \\ DOI 10.1007/s00191-014-0341-0}

The original version of this article unfortunately contained errors.

[Section 3.1, Page7]

Equation (2b) should be modified.

The condition for "dynamic diminishing return" should be changed as the following:

$$
\text { dynamic diminishing return for } f^{\prime}<0 \text { when } n>\frac{N^{*}}{2}
$$

should be replaced by

$$
f^{\prime}<0 \text { when } \frac{N^{*}}{2}<n<N^{*}
$$

[Section 3.2, Page 11]

Equation $(5 \mathrm{c})$ is not corrected.

The original equation $(5 \mathrm{c})$

$$
\frac{1}{2}\left(C_{1}+C_{2}\right) \leq n_{1}^{*}+n_{2}^{*}=\frac{\left(C_{1}+C\right)_{2}}{1+\beta} \leq\left(C_{1}+C_{2}\right)
$$

The online version of the original article can be found at http://dx.doi.org/10.1007/s00191-014-0341-0.

P. Chen $(\square)$

Center for New Political Economy, Fudan University, Shanghai, China

e-mail: pchen@nsd.pku.edu.cn 
should be replaced by the following equation:

$$
\frac{1}{2}\left(C_{2}+C_{2}\right) \leq\left(n_{1}^{*}+n_{2}^{*}\right)=\frac{\left(C_{1}+C_{2}\right)}{1+\beta} \leq\left(C_{1}+C_{2}\right)
$$

In the same page 11 , the last sentence of the next paragraph, the condition for (ii) Old and new technology coexist so that ......,

Here, $\left(\mathrm{C}_{2}-\mathrm{n} 2^{*}\right)>0$ should be $\left(C_{2}-n_{2}^{*}\right)>0$. 